\title{
ULTRAESTRUTURA DO ESPERMATOZOIDE DE ALGUMAS ESPÉCIES DE CARANGUEJOS PANOPEIDAE E XANTHIDAE
}

\author{
Salti, F.C. ${ }^{1,2,}{ }^{*}$; Mataqueiro, M.F. ${ }^{1} \&$ Zara, F.J. ${ }^{1}$ \\ ${ }^{1}$ Universidade Estadual Paulista (UNESP), Faculdade de Ciências Agrárias e Veterinárias, Campus Jaboticabal - SP, \\ Brasil, Laboratório de Morfologia de Invertebrados (IML), Departamento de Biologia Aplicada à Agropecuária. \\ ${ }^{2}$ Universidade Estadual Paulista (UNESP), Instituto de Biociências, Campus Rio Claro - SP, Brasil. \\ *Autor correspondente: fernandasalti_@hotmail.com
}

\begin{abstract}
Xanthoidea tem passado por revisões taxonômicas quanto à organização das famílias. Neste trabalho, descrevemos a ultraestrutura do espermatozoide de algumas espécies de Panopeidae e Xanthidae a fim de verificar caracteres específicos para as diferentes famílias. A região posterior do vaso deferente de Panopeus harttii (Smith, 1869), Panopeus rugosus (A. Milne-Edwards, 1880), Hexapanopeus angustifrons (Benedict e Rathbun, 1891), Micropanope nuttingi (Rathbun, 1898), Cataleptodius parvulus (Fabricius, 1793) e Platypodiella spectabilis (Herbst, 1794) foi fixada e processada para rotina de microscopia eletrônica de transmissão. Todas as espécies de Xanthidae e $H$. angustifrons possuem espermatóforos cleistospérmicos (um espermatozoide por espermatóforo), enquanto Panopeus spp. (H. Milne-Edwards, 1834) não apresentaram espermatóforos. Em ambas as famílias, o espermatozoide tem como características a dobra periopercular, quatro camadas acrossomais concêntricas, anel xanthide junto à câmara perforatorial, anel espessado na base desta câmara e dobras nucleares arredondadas. Em Panopeidae, a câmara perforatorial é claviforme com pequenas diferenças entre as espécies, enquanto em Xanthidae todas são lanceoladas. Em Panopeus spp., o opérculo é pouco saliente e o anel opercular acessorio é plano, enquanto em $H$. angustifrons o opérculo é saliente e o anel opercular é curvo. Em Xanthidae, a morfologia saliente do opérculo ocorreu em M. nuttingi e C. parvulus, sendo pouco saliente em Pl. spectabilis. O anel opercular acessório é plano para todos os Xanthidae estudados. A camada intermediária apresentou variação, sendo estriada ou homogênea em ambas as famílias. Neste trabalho, é apresentado pela primeira vez, espermatozoides livres ou espermatóforos cleistospérmicos para animais exclusivamente marinhos, sendo esta característica comum a caranguejos de água doce e uma espécie eurialina. Com base nas filogenias propostas para o grupo, Xanthoidea é monofilético, entretanto, Xanthidae é parafilético com Panopeidae. Porém, os caracteres do espermatozoide apontaram para somente uma diferença, a qual está relacionada à câmara perforatorial, incluindo outras espécies da literatura. A ocorrência de uma só característica parece ser muito pouco para separar as famílias com auxílio da espermiotaxonomia. Assim, será necessário estudar mais espécie de Panopeidae e Xanthidae para confirmar esta diferença. Os demais caracteres variados entre as famílias parecem ser convergentes.
\end{abstract}

Palavras-chave: Brachyura, espermiotaxonomia, taxonomia.

Financiamento: CAPES DS 001 (Bolsa Mestrado); CAPES CIMAR II \#1989/2014-5; FAPESP BIOTA \#2010/50188-8. 